\title{
Prenatal Oral Health Education in U.S. Dental Schools and Obstetrics and Gynecology Residencies
}

\begin{abstract}
Megan Curtis, M.D.; Hugh J. Silk, M.D., M.P.H.; Judith A. Savageau, M.P.H.
Abstract: Prenatal oral health $(\mathrm{POH})$ is an important health issue, but dental and obstetrical clinicians are not meeting the oral health needs of pregnant patients. This study evaluates how training contributes to this paradox with a national survey of sixty dental school deans and 240 obstetrics and gynecology residency program directors. Response rates were 53 percent and 40 percent for deans and program directors, respectively. According to the respondents, 94 percent of responding dental schools provided $\mathrm{POH}$ education, only 39 percent of responding residencies taught $\mathrm{POH}$, and 65 percent of responding deans and 45 percent of responding program directors were aware of current $\mathrm{POH}$ guidelines. The residencies exposing trainees to guidelines were three times more likely to have $\mathrm{POH}$ training. Barriers to $\mathrm{POH}$ education were reported to include too few pregnant patients in clinical settings (for responding dental schools) and lack of faculty expertise (for responding residencies). The majority of responding deans and program directors agreed they would add more $\mathrm{POH}$ education if the American College of Obstetricians and Gynecologists issued a policy statement or practice bulletin. The majority of responding dental deans reported teaching POH in their schools, but clinical exposure was limited; less than half of responding residencies included POH training. Future efforts should include distribution of $\mathrm{POH}$ guidelines/consensus statements to educators and learners, increasing exposure of dental students to pregnant patients, and developing faculty expertise in residencies.
\end{abstract}

Dr. Curtis is a family medicine resident, Swedish Family Medicine Residency First Hill, Seattle, WA; Dr. Silk is Clinical Associate Professor, Department of Family Medicine and Community Health, University of Massachusetts Medical School; and Ms. Savageau is Associate Professor, Department of Family Medicine and Community Health, University of Massachusetts Medical School. Direct correspondence and requests for reprints to Dr. Megan Curtis, 1711 East Olive Way, \#217, Seattle, WA 98102; megancurtis@outlook.com.

Keywords: dental education, oral health education, women's health, obstetrics and gynecology, oral health, pregnancy

Submitted for publication 10/22/12; accepted 12/18/12

$\mathrm{T}$ The status of a woman's oral health, particularly if periodontal disease exists, has been linked to numerous systemic health conditions. Periodontitis affects 35 percent of women of childbearing age $^{1}$ and has been linked to pregnancy and infant health outcomes including low birth weight and preterm birth. ${ }^{2,3}$ Associations between periodontal disease and pre-eclampsia and gestational diabetes have also been shown in pregnant women. ${ }^{4-7}$

There are numerous additional reasons to address oral health care in pregnancy. Oral disease treatment makes women feel better, is safe, and reduces the risk for other long-term health outcomes to which periodontitis has been linked, including diabetes and heart disease. ${ }^{8,9}$ Additionally, the promotion of oral health during the prenatal period improves overall mouth hygiene and lowers the rate of caries for mother and infant. There is strong evidence that a mother passes her caries risk to her newborn in the first two years of life via vertical transmission of caries-causing bacteria (i.e., streptococcus mutans). ${ }^{10,11}$ Finally, mothers who seek dental care during pregnancy are more likely to be aware of the dental needs of their infants and seek dental care for their other children. ${ }^{12}$

The risks of oral disease in pregnancy led perinatal health experts to create prenatal oral health $(\mathrm{POH})$ guidelines. The New York State Department of Health created an evidence-based $\mathrm{POH}$ consensus document in 2006, which was revised in 2010 by the California Dental Association (CDA) in collaboration with the American College of Obstetricians and Gynecologists (ACOG). ${ }^{13}$ These state guidelines provide specific information for prenatal, oral health, and pediatric care professionals to address the oral health care of the mother during and after pregnancy; in the absence of national guidelines, they have been used throughout the country. ${ }^{14}$ Since our survey was 
conducted, a national consensus statement was released, the result of an expert workgroup convened in 2011 (published in 2012) by the Health Resources and Services Administration (HRSA) in collaboration with the American Dental Association (ADA) and ACOG. ${ }^{15}$

Despite the existence of the 2006 and 2010 guidelines, $\mathrm{POH}$ has not been addressed sufficiently in clinical practice. Only 34 percent of women report visiting the dentist when pregnant, and only half of women who have a dental problem during pregnancy see a dentist. ${ }^{16}$ Surveys of obstetricians have found that only 22 percent of the respondents look into patients' mouths at the initial prenatal examination and less than half rarely or never recommend a dental examination during pregnancy. ${ }^{17}$ These findings are perplexing as 80 percent of obstetricians surveyed recognize the importance of dental care during pregnancy and the potential negative impacts on pregnancy outcomes..$^{18}$ On the dental side, 77 percent of obstetricians surveyed reported having patients decline dental care because of pregnancy. One explanation is that while 97 percent of dentists in one survey felt that pregnant women should receive oral health screens, 48 percent felt uncomfortable treating pregnant women, safety of dental procedures during pregnancy being the greatest concern. ${ }^{19}$

It is unclear why dentists and obstetricians do not have more confidence and give priority to addressing this important topic with patients. One reason might be lack of training. Currently the American Dental Education Association (ADEA) competencies for the new general dentist has only one competency (6.1 under Patient Care) that briefly references managing "the unique needs of women," 20 and the Accreditation Committee of Graduate Medical Education (ACGME) has no specific POH requirements for obstetrics and gynecology residency programs. ${ }^{21}$ Furthermore, surveys have found that only 26 percent of dental schools sufficiently cover POH and only 30 percent of U.S. medical schools have an oral health curriculum. ${ }^{22,23}$ A specific evaluation of $\mathrm{POH}$ education in dental schools has yet to be performed, nor have data been gathered about the extent of $\mathrm{POH}$ education in obstetrics and gynecology residency programs. To investigate $\mathrm{POH}$ training in graduate education, we devised two national surveys (one for dental school deans and one for obstetrics and gynecology program directors) with the goal of assessing the current status of $\mathrm{POH}$ training, barriers to training, and associations with more robust $\mathrm{POH}$ education.

\section{Methods}

As a cross-sectional study, two eight-question surveys were created: one for dental schools and one for obstetrics and gynecology residency programs. The survey questions covered program demographics (size, program type, location) and $\mathrm{POH}$ curriculum (number of hours, specific topics addressed, barriers to teaching $\mathrm{POH}$, and evaluation of oral health competence). Also included were questions about awareness and use of current guidelines and attitudes regarding the importance of $\mathrm{POH}$ education and potential formal policy changes. (Note that our survey was conducted before the release of the 2012 national consensus statement ${ }^{15}$ and was thus based on only the 2006 and 2010 state guidelines. ${ }^{13,14}$ ) The study was reviewed by the Institutional Review Board at the University of Massachusetts Medical School and determined to be exempt.

An online search was conducted of professional association websites to identify the deans of U.S. dental schools (members of the ADA) and the program directors of all U.S. obstetrics and gynecology residency programs (members of ACOG). The surveys were sent out electronically using SurveyMonkey to sixty dental school deans and 240 program directors one week following an advance e-mail explaining the purpose of the survey. One dental school was removed from the study after self-identifying that the school was still being created.

Each survey was sent electronically every two weeks for a total of three times, with reminders being sent only to nonrespondents. A paper survey was then mailed to the remaining nonrespondents, including those who had opted out of receiving electronic surveys or whose e-mails were undeliverable. A final reminder e-mail was sent to obstetrics and gynecology program coordinators asking them to remind their program directors.

Data were analyzed using SPSS statistical software (Version 17.0, SPSS, Inc., Chicago, IL, USA). Univariate statistics were used to describe the study population, particulars of their oral health curricula, awareness of resources, and barriers to inclusion of $\mathrm{POH}$ topics. Based on the categorical or continuous nature of the study variables (using chi-square tests and t-tests), relationships were examined between the number of training hours in oral health, use of current guidelines, select demographic data, and attitudes about $\mathrm{POH}$ and policy changes using an alpha of 0.05 to denote statistical significance. Likert 
scale questions (with response options of strongly disagree, disagree, neutral, agree, and strongly agree) were recoded for bivariate analyses to "agree," which included strongly agree and agree, and "disagree," which included the remaining answer choices.

\section{Results}

Thirty-one of fifty-nine dental school deans responded (response rate of 52.5 percent), while ninety-seven of 240 obstetrics and gynecology program directors responded (40.4 percent). Institutional characteristics of the participating programs are shown in Table 1.

Nearly all (93.6 percent) of the dental respondents reported their schools provided at least one hour of $\mathrm{POH}$ education, with most schools (61.3 percent) providing three or more hours. The majority (61.9 percent) of obstetrics and gynecology respondents reported their programs provided no $\mathrm{POH}$ education. Of those programs that reported $\mathrm{POH}$ education, most provided one to two hours (32.0 percent), with only six (6.2 percent) providing three to four hours; no programs provided more than four hours.

Topics covered in the curricula of responding schools and programs with at least one hour of $\mathrm{POH}$ education are shown in Figure 1. Six of seven surveyed topics were covered by 97-100 percent of responding dental schools. The topics covered by responding residency programs ranged from 94.4 percent (relationship between periodontal disease and adverse pregnancy outcomes) to a low of 40 percent (oral screening examination). Almost all responding dental school deans ( 96.8 percent) reported that their students have the opportunity to see pregnant patients during their clinical training. Nearly twothirds (62.9 percent) of responding obstetrics and gynecology program directors reported encouraging their residents to address the oral health concerns of patients during prenatal care. When asked about evaluation, 75 percent of responding dental school deans and 18.6 percent of responding obstetrics and gynecology residency directors reported assessing trainees on $\mathrm{POH}$ competencies.

The study participants were asked about their awareness and use of the 2006 or 2010 evidencebased POH guidelines. Two-thirds (64.5 percent) of responding dental school deans were aware of the guidelines, and 41.4 percent said their curricula exposed students to either or both documents. Among these dental respondents, there were no significant
Table 1. Institutional information on U.S. dental schools $(\mathrm{N}=31)$ and obstetrics/gynecology residency programs $(\mathrm{N}=97)$ participating in study

Number Percentage

\begin{tabular}{|c|c|c|}
\hline \multicolumn{3}{|l|}{ Dental Schools } \\
\hline \multicolumn{3}{|l|}{ Size (students per matriculating class) } \\
\hline$<70$ & 10 & $33.3 \%$ \\
\hline $70-90$ & 10 & $33.3 \%$ \\
\hline$>90$ & 10 & $33.3 \%$ \\
\hline Total & 30 & \\
\hline \multicolumn{3}{|l|}{ Type } \\
\hline University-based & 31 & $100 \%$ \\
\hline $\begin{array}{l}\text { Community-based, university- } \\
\text { affiliated }\end{array}$ & 0 & 0 \\
\hline Community-based, non-affiliated & 0 & 0 \\
\hline Military & 0 & 0 \\
\hline Total & 31 & \\
\hline \multicolumn{3}{|l|}{ Region } \\
\hline North/Northeast & 6 & $19.4 \%$ \\
\hline Midwest & 10 & $32.3 \%$ \\
\hline South & 8 & $25.8 \%$ \\
\hline West & 7 & $22.6 \%$ \\
\hline Total & 31 & \\
\hline \multicolumn{3}{|l|}{ OB/GYN Residencies } \\
\hline \multicolumn{3}{|l|}{ Size (PGY-1 residents per year) } \\
\hline $1-4$ & 42 & $45.2 \%$ \\
\hline $5-7$ & 36 & $38.7 \%$ \\
\hline$>7$ & 15 & $16.1 \%$ \\
\hline Total & 93 & \\
\hline \multicolumn{3}{|l|}{ Type } \\
\hline University-based & 52 & $55.3 \%$ \\
\hline $\begin{array}{l}\text { Community-based, university- } \\
\text { affiliated }\end{array}$ & 32 & $34.0 \%$ \\
\hline Community-based, non-affiliated & 8 & $8.5 \%$ \\
\hline Military & 2 & $2.1 \%$ \\
\hline Total & 94 & \\
\hline \multicolumn{3}{|l|}{ Region } \\
\hline North/Northeast & 25 & $26.6 \%$ \\
\hline Midwest & 39 & $41.5 \%$ \\
\hline South & 17 & $18.1 \%$ \\
\hline West & 13 & $13.8 \%$ \\
\hline Total & 94 & \\
\hline
\end{tabular}

Note: Individual question sample sizes may not total to the full sample of respondents due to sporadic missing data. Maximum potential denominator was 31 for dental school respondents and 97 for OB/GYN residency respondents.

associations between awareness and exposure of guidelines and hours of training. While 44.8 percent of responding obstetrics and gynecology program directors reported being aware of the guidelines, only 29.2 percent said their programs exposed residents to the documents. Among these program directors, 


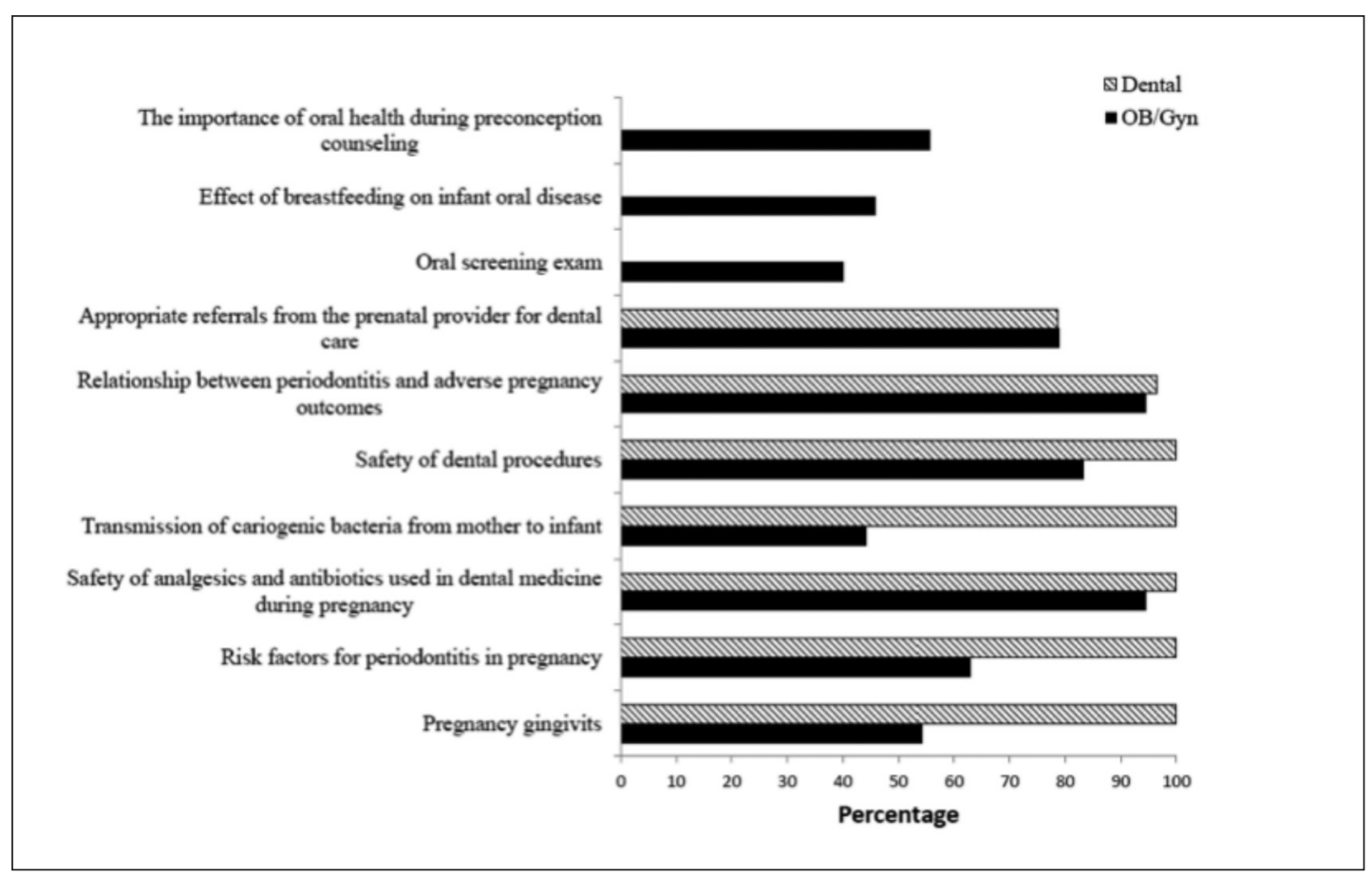

Figure 1. Prenatal oral health topics covered in responding U.S. dental schools and OB/GYN residency programs that teach at least one hour of prenatal oral health education

Note: The topics "oral screening exam," "effect of breastfeeding on infant oral disease," and "the importance of oral health during preconception counseling" were deemed obvious in dental education or less relevant and therefore were not included on the survey sent to dental school deans.

those aware of the guidelines were twice as likely (66.7 percent vs. 31.7 percent; $p<0.001$ ) to have at least one hour of $\mathrm{POH}$ education in their curricula, whereas program directors unaware of the guidelines were twice as likely (68.3 percent vs. 33.3 percent; $\mathrm{p}<0.001$ ) to have zero hours of $\mathrm{POH}$ education. More notably, responding program directors who said their curricula exposed residents to the guidelines were more than three times as likely (52.8 percent vs. 15.0 percent; $p<0.001$ ) to include at least one hour of $\mathrm{POH}$ education, while directors who did not expose residents to the document were almost twice as likely (85.0 percent vs. 47.2 percent; $p<0.001$ ) to have no $\mathrm{POH}$ education in their curricula.

The most prevalent reported barriers to teaching $\mathrm{POH}$ in dental schools were competing clinical priorities for students' time and effort and space in the curriculum (both 67.7 percent) and too few pregnant patients available during students' clinical training (43.3 percent). Lack of faculty expertise (25.8 percent), faculty interest (20.7 percent), and unclear/insufficient evidence for POH management (12.9 percent) were less commonly identified by the dental deans. The most significant reported barriers for obstetrics and gynecology residencies were competing clinical priorities for residents' time and effort (85.1 percent of respondents), space in the curriculum (73.7 percent), lack of faculty expertise (70.5 percent), and lack of faculty interest in $\mathrm{POH}$ (66.3 percent).

The results of questions addressing respondents' attitudes regarding $\mathrm{POH}$ education are shown in Table 2 (dental schools) and Table 3 (residency programs). The vast majority of responding dental school deans and residency program directors agreed that it is important for their trainees to address basic oral health care issues of their prenatal patients, while less than half of the responding dental school deans and less than one-quarter of the responding program directors agreed that there should be official requirements or competencies for POH. The majority of both groups agreed that the other specialty should be 
Table 2. Responding U.S. dental school deans' opinions on prenatal oral health education, by percentage and number of respondents to each question

\begin{tabular}{|c|c|c|c|c|c|}
\hline Survey Statement & $\begin{array}{l}\text { Strongly } \\
\text { Disagree }\end{array}$ & Disagree & Neutral & Agree & $\begin{array}{l}\text { Strongly } \\
\text { Agree }\end{array}$ \\
\hline $\begin{array}{l}\text { It is important for dental students to address the specific } \\
\text { oral health care issues of pregnant patients. }\end{array}$ & $3.2 \%(1)$ & 0 & 0 & $19.4 \%(6)$ & $77.4 \%(24)$ \\
\hline $\begin{array}{l}\text { I am satisfied with the level of competence that my students } \\
\text { achieve in POH by graduation. }\end{array}$ & $3.2 \%(1)$ & $9.7 \%(3)$ & $16.1 \%(5)$ & $51.6 \%(16)$ & $19.4 \%(6)$ \\
\hline $\begin{array}{l}\text { It is important for obstetricians to address their patients' } \\
\text { basic oral health care issues. }\end{array}$ & $3.2 \%(1)$ & 0 & 0 & $41.9 \%(13)$ & $54.8 \%(17)$ \\
\hline $\begin{array}{l}\text { CODA should add POH to its Accreditation Standards for } \\
\text { Dental Education Programs. }\end{array}$ & $6.5 \%(2)$ & $25.8 \%(8)$ & $25.8 \%(8)$ & $29.0 \%(9)$ & $12.9 \%(4)$ \\
\hline ADEA should make $\mathrm{POH}$ an educational priority for & $3.2 \%(1)$ & $16.1 \%(5)$ & $54.8 \%(17)$ & $12.9 \%(4)$ & $12.9 \%(4)$ \\
\hline
\end{tabular}
dental schools.

Note: Individual question sample sizes may not total to the full sample of respondents due to sporadic missing data. Maximum potential denominator was 31 for dental school dean respondents.

Table 3. Responding U.S. OB/GYN residency program directors' opinions on prenatal oral health education, by percentage and number of respondents to each question

\begin{tabular}{|c|c|c|c|c|c|}
\hline Survey Statement & $\begin{array}{l}\text { Strongly } \\
\text { Disagree }\end{array}$ & Disagree & Neutral & Agree & $\begin{array}{c}\text { Strongly } \\
\text { Agree }\end{array}$ \\
\hline $\begin{array}{l}\text { It is important for OB/GYN residents to address basic oral } \\
\text { health care issues of their prenatal patients. }\end{array}$ & $2.1 \%(2)$ & $2.1 \%(2)$ & $19.8 \%(19)$ & $60.4 \%(58)$ & $15.6 \%(15)$ \\
\hline $\begin{array}{l}\text { I am satisfied with the level of competence that my residents } \\
\text { achieve in prenatal oral health by graduation. }\end{array}$ & $3.1 \%(3)$ & $21.9 \%(21)$ & $42.7 \%(41)$ & $31.3 \%(30)$ & $1.0 \%(1)$ \\
\hline $\begin{array}{l}\text { It is important for dentists to be trained in the specific oral } \\
\text { health care issues of pregnant patients. }\end{array}$ & $1.1 \%(1)$ & $2.1 \%(2)$ & $8.5 \%(8)$ & $45.7 \%(43)$ & $42.6 \%(40)$ \\
\hline $\begin{array}{l}\text { ACGME should add prenatal oral health competencies for } \\
\text { OB/GYN residency programs. }\end{array}$ & $12.6 \%(12)$ & $28.4 \%(27)$ & $34.7 \%(33)$ & $17.9 \%(17)$ & $6.3 \%(6)$ \\
\hline
\end{tabular}

Note: Individual question sample sizes may not total to the full sample of respondents due to sporadic missing data. Maximum potential denominator was 97 for OB/GYN residency respondents.

trained to address $\mathrm{POH}$ with patients. The vast majority (73.3 percent of responding dental school deans and 90.6 percent of responding program directors) reported that if ACOG had a formal policy statement or practice bulletin on $\mathrm{POH}$ care, they would be influenced to include more $\mathrm{POH}$ training in their curricula. Meanwhile only a quarter (25.8 percent) of responding dental deans felt that ADEA should make $\mathrm{POH}$ an educational priority for dental schools.

Responding deans of dental schools with three or more $\mathrm{POH}$ training hours were almost twice as likely ( 84.6 percent vs. 47.1 percent; $\mathrm{p}=0.034$ ) to agree that the Commission on Dental Accreditation (CODA) should add $\mathrm{POH}$ to its accreditation standards. Those dental school deans reporting zero to two hours of training were more than three times as likely ( 58.3 percent vs. 17.7 percent; $\mathrm{p}=0.023$ ) to identify the barrier "too few pregnant patients available for students during clinical training." All responding dental school deans who disagreed that they were satisfied with the level of student competence in $\mathrm{POH}$ by graduation reported that they would be influenced by a formal policy from ACOG to include more prenatal training $(\mathrm{p}=0.035)$.

Responding directors of obstetrics and gynecology programs with one or more hours of $\mathrm{POH}$ education were twice as likely to teach their residents to address oral health concerns of their prenatal patients (47.5 percent vs. 22.2 percent; $p=0.013$ ). Those directors who agreed that the ACGME should add $\mathrm{POH}$ competencies for obstetrics and gynecology residency programs were twice as likely (36.1 percent vs. 17.0 percent; $p=0.034$ ) to have at least one hour of $\mathrm{POH}$ education in their programs. Bivariate analysis 
revealed very little difference among geographic regions and none among the other institutional characteristics for both dental schools and residencies.

\section{Discussion}

Not surprisingly, our study found that a higher percentage of dental schools than obstetrics and gynecology residency programs were formally addressing $\mathrm{POH}$ in their curricula and including more hours covering this topic. Even if one concludes that one to two hours of prenatal oral health education is adequate, the majority of responding obstetrics and gynecology residency programs do not have any oral health hours in their curricula. At a bare minimum, it would be prudent for obstetrical residents to be able to assess the mouth in relevant clinical situations and make proper referrals. This lack of training is especially concerning for women who only see their obstetrician/gynecologist during child-bearing years for health care maintenance and preventive services.

Our results confirm those reported in previous studies that dentists and obstetricians believe that $\mathrm{POH}$ is an important topic. ${ }^{18,19}$ Additionally, the evidence and importance around $\mathrm{POH}$ are unlikely barriers to providing more training, suggesting that the current evidence is sufficient for academic administrators to consider it a worthy clinical topic to teach their trainees.

In our study, the strongest associations with greater hours of $\mathrm{POH}$ education were seen for awareness of the evidence-based guidelines by obstetrics and gynecology program directors and even more markedly with exposure of residents to those documents. Unfortunately, our findings suggest that less than half of dental students and less than one-third of obstetrics and gynecology residents are being exposed to these comprehensive guidelines. Furthermore, the vast majority of respondents from both disciplines indicated that if ACOG issued a formal policy or practice bulletin on $\mathrm{POH}$, they would be influenced to include more $\mathrm{POH}$ in their curricula. This is especially true for those dental schools with less $\mathrm{POH}$ and dental deans unsatisfied with their students' competence. It remains to be seen what the effect of the 2012 national consensus statement will have on prenatal education. Although ACOG collaborated on the consensus statement, it is not an official ACOG policy statement or practice bulletin, which traditionally has had the greatest influence on obstetrical practice and teaching. At the very least, efforts focused on distribution of the consensus statement to deans, program directors, and their faculties and students could be one way to increase $\mathrm{POH}$ training in the United States.

The most commonly reported barriers to teaching more $\mathrm{POH}$ for both disciplines in our study were space in the curriculum and competing clinical priorities for trainees, a common barrier in academic programs. For this reason, schools and programs use accreditation requirements to triage the most important topics to teach. However, even though the majority of respondents in our study agreed that $\mathrm{POH}$ is an important topic to address during training, only a minority agreed that CODA and ACGME should add formal requirements or that ADEA should make $\mathrm{POH}$ an educational priority. Interestingly, those respondents with more $\mathrm{POH}$ education in their curricula were more likely to support formal requirements, while those with less or no POH education were less likely to support them. Perhaps programs that do not have $\mathrm{POH}$ education are already lacking space for other clinical priorities, so an official requirement would only put more pressure on an already full curriculum. If this is the case, then future efforts to increase $\mathrm{POH}$ education should focus on efforts other than school/residency requirements. ADEA is already working on becoming more specific about women's health in its predoctoral competencies and providing better resources. ${ }^{24}$

Interestingly, even though the responses from dental deans in our study suggest that most dental schools expose students to pregnant patients during training, almost half of our respondents identified a lack of prenatal patient visits as a barrier to teaching more $\mathrm{POH}$. One explanation for the shortage of patients could be the lack of faculty expertise noted by 26 percent of responding dental school deans. Also, more than half of the obstetrics and gynecology respondents indicated a lack of faculty expertise and interest in $\mathrm{POH}$, which could lead to fewer referrals to dentists and dental school clinics. Another influence on low rates of prenatal patients in dental school clinics may be the finding previously reported that only half of pregnant patients with dental concerns seek dental care. ${ }^{16}$

We acknowledge the following limitations of this study. First, recall bias may have played a role as the survey required detailed knowledge of the curriculum. Respondents lacking knowledge in certain areas may have been more likely to skip particular questions. Likewise, respondents with little to no $\mathrm{POH}$ education in their curricula may have been less 
likely to respond, which would lead to an overestimation of the amount of $\mathrm{POH}$ education in the schools and programs. Future research on this topic might ask residents/students directly (though recall bias would remain), assess residents/students on their $\mathrm{POH}$ skills (which may be costly), or obtain specific curriculum documentation for each individual program. Second, our response rates were 53 percent for dental schools and 40 for obstetrics and gynecology programs, and while acceptable for samples of health care professionals, the findings may not be generalizable to all dental schools and obstetrics and gynecology residencies in the United States. However, all program sizes and regions of the country were represented for both surveys.

\section{Conclusion}

Dentists, obstetricians, and patients themselves all play important roles in oral health care for pregnant patients and therefore require more education about oral health issues during the prenatal period. Efforts for obstetrics residency programs could focus on increasing the number of presentations at academic conferences and meetings, as well as journal articles on oral health, to make faculty members more aware. Faculty expertise in $\mathrm{POH}$ would be expected to follow an increase in faculty interest. In this age of "patient-centered health homes" working as interprofessional teams, linking dental school clinics with obstetrics and gynecology residencies for training exposure and referral networks may make these efforts even more efficient. Graduate programs should be encouraged to use existing curricula with proven results. One such oral health curriculum, Smiles for Life, has a POH module that includes faculty guidelines and test questions. ${ }^{25}$

Faculty members should also be made more aware of current state and national efforts. The Division of Oral Health at the Centers for Disease Control and Prevention (CDC) is specifically targeting attitudes around the safety of dental treatment during pregnancy. ${ }^{26}$ Meanwhile, the Association of State and Territorial Dental Directors (ASTDD) has created a Perinatal Oral Health Committee to serve as a central resource for state oral health programs regarding issues, policies, and educational materials relating to prenatal and early childhood oral health. ${ }^{27}$ These efforts could work synergistically with dental schools and residency programs, as well as state oral health coalitions that are already working on strategies to increase oral health education for medical and dental learners, as outlined in their state oral health plans.

Our study found that the majority of responding obstetrics and gynecology programs did not include $\mathrm{POH}$ in their curricula, while over half of responding dental schools were teaching at least three hours of $\mathrm{POH}$. It was encouraging to find that both responding dentists and obstetricians agreed that $\mathrm{POH}$ is an important clinical topic to teach trainees. Future efforts to increase $\mathrm{POH}$ training should include promoting the new national consensus statement on pregnancy oral health and previous evidence-based guidelines to deans, program directors, students, and residents. Efforts should also focus on the identification, creation, and support of oral health experts in obstetrics and gynecology programs.

\section{Acknowledgments}

The authors would like to thank Gail Sawosik, M.B.A. (University of Massachusetts Medical School Department of Family Medicine and Community Health) and Parag Kunte, M.P.H. (University of Massachusetts Medical School Center for Health Policy and Research) for their assistance with data analysis, funded by the University of Massachusetts Medical School Department of Family Medicine and Community Health, and Laura Silk, M.D. (Montachusett Women's Health, Leominster, MA) and Penny Armstrong, C.N.M. (retired) for their editing and guidance with a written presentation. We would also like to thank the University of Massachusetts Medical School's Senior Scholars Program in the Office of Undergraduate Medical Education for its funding and support. The findings of our study were presented as a Poster Presentation at the American Public Health Association's 140th Annual Meeting \& Exposition, October 27-31, 2012, San Francisco, CA.

\section{REFERENCES}

1. Silk H, Douglass AB, Douglass JM, Silk L. Oral health during pregnancy. Am Fam Phys 2008;77(8):1139-44.

2. Clothier B, Stringer M, Jeffcoat MK. Periodontal disease and pregnancy outcomes: exposure, risk, and intervention. Best Pract Res Clin Obstet Gynaecol 2007;21(3):451-66.

3. Vergnes JN, Sixou M. Preterm low birthweight and maternal periodontal status: a meta-analysis. Am J Obstet Gynecol 2007;196(2):135.

4. Xiong X, Elkind-Hirsch KE, Vastardis S, Delarosa RL, Pridjian G, Buekens P. Periodontal disease is associated with gestational diabetes mellitus: a case-control study. J Periodontol 2009;80(11):1742-9.

5. Xiong X, Buekens P, Vastardis S, Pridjian G. Periodontal disease and gestational diabetes mellitus. Am J Obstet Gynecol 2006;195(4):1086-9. 
6. Ruiz DR, Romito GA, Dib SA. Periodontal disease in gestational and type 1 diabetes mellitus pregnant women. Oral Dis 2011;17(5):515-21.

7. Canakci V, Canakci CF, Yildirim A, Ingec M, Eltas A, Erturk A. Periodontal disease increases the risk of severe pre-eclampsia among pregnant women. J Clin Periodontol 2007;34(8):639-45.

8. Azarpazhooh A, Tenenbaum HC. Separating fact from fiction: use of high-level evidence from research syntheses to identify diseases and disorders associated with periodontal disease. J Can Dent Assoc 2012;78:c25.

9. Bahekar AA, Singh S, Saha S, Molnar J, Arora R. The prevalence and incidence of coronary heart disease is significantly increased in periodontitis: a meta-analysis. Am Heart J 2007;154(5):830-7.

10. Berkowitz RJ. Acquisition and transmission of mutans streptococci. J Calif Dent Assoc 2003;31(2):135-8.

11. Douglass JM, Li Y, Tinanoff N. Systematic review of the association between mutans streptococci in primary caregivers and mutans streptococci and dental caries in their children. Pediatr Dent 2008;30(5):375-87.

12. Lin DL, Harrison R, Aleksejuniene J. Can a prenatal dental public health program make a difference? J Can Dent Assoc 2011;77:b32.

13. New York Public Health Department. Oral health care during pregnancy and early childhood practice guidelines. 2006. At: www.health.state.ny.us/publications/0824.pdf. Accessed: December 10, 2012.

14. California Dental Association Foundation and American College of Obstetricians and Gynecologists, District IX. Oral health during pregnancy and early childhood: evidence-based guidelines for health professionals. J Calif Dent Assoc 2010;38(6):391-403,405-40.

15. Oral Health Care During Pregnancy Expert Workgroup. Oral health care during pregnancy: a national consensus statement-summary of an expert workgroup meeting. Washington, DC: National Maternal and Child Oral Health Resource Center, 2012. At: www.mchoralhealth.org/materials/consensus_statement.html. Accessed: December 10, 2012.

16. Gaffield ML, Gilbert BJ, Malvitz DM, Romaguera R. Oral health during pregnancy: an analysis of information collected by the pregnancy risk assessment monitoring system. J Am Dent Assoc 2001;132(7):1009-16.
17. Wilder R, Robinson C, Jared HL, Lieff S, Boggess K. Obstetricians' knowledge and practice behaviors concerning periodontal health and preterm delivery and low birth weight. J Dent Hyg 2007;4:81

18. Morgan MA, Crall J, Goldenberg RL, Schulkin J. Oral health during pregnancy. J Matern Fetal Neonatal Med 2009;22(9):733-9.

19. Strafford KE, Shellhaas C, Hade EM. Provider and patient perceptions about dental care during pregnancy. J Matern Fetal Neonatal Med 2008;21(1):63-71.

20. American Dental Education Association. ADEA competencies for the new general dentist. J Dent Educ 2013;77(7):899-901.

21. ACGME program requirements for graduate medical education in obstetrics and gynecology. 2008. At: www. acgme.org/acgmeweb/Portals/0/PFAssets/ProgramReq uirements/220obstetricsandgynecology01012008.pdf. Accessed: December 10, 2012.

22. Wilder RS, Iacopino AM, Feldman CA, Guthmiller J, Linfante J, Lavigne S, Paquette D. Periodontal-systemic disease education in U.S. and Canadian dental schools. J Dent Educ 2009;73(1):38-52.

23. Ferullo A, Silk H, Savageau JA. Teaching oral health in U.S. medical schools: results of a national survey. Acad Med 2011;86(2):226-30.

24. Women's health in the dental school curriculum, 2012: survey report and recommendations. At: http://sgwhc. org/resources/reports-guidelines/womens-health-in-thedental-school-curiculum-2012/. Accessed: December 10, 2012.

25. Douglass AB, Maier R, Deutchman M, Douglass JM, Gonsalves W, Silk H, et al. Smiles for life: a national oral health curriculum. 3rd ed. Module 5: oral health and the pregnant patient. Society of Teachers of Family Medicine, 2010. At: www.smilesforlifeoralhealth.org. Accessed: December 10, 2012.

26. Ressler-Maerlender J, Krishna R, Robison V. Oral health during pregnancy: current research. J Womens Health 2005;14(10):880-2.

27. Association of State and Territorial Dental Directors. Perinatal oral health committee. At: www.astdd.org/ perinatal-and-early-childhood-committee/. Accessed: December 10, 2012. 